\section{X-Ray Powder Diffraction Data of a New Compound $\mathrm{Na}_{2} \mathrm{Ca}_{4} \mathrm{Mg}_{2} \mathrm{Si}_{4} \mathrm{O}_{15}$ \\ By Robert Hausner \\ Research Institute, Veitscher Magnesitwerke AG, Magnesitstr. \\ 2 A-8700 Leoben, Austria \\ Michael Suppaner \\ Department of Geological Sciences of the Montanuniversität, A-8700 Leoben, Austria}

The following entries, omitted in the original publication of the above article, should be entered in Table 2 .

$\begin{array}{rrlr}1.919 & 74 & 620, \overline{713} & 47.341 \\ 1.987 & 2 & \overline{6} 22 & 47.919\end{array}$

In the data entry, Table 2, beginning 1.634 the bar above the 114 entry was incorrectly positioned. It should $\overline{1} 14$.
Powder Diffraction Data for Nitroguanidine, $\mathrm{C}\left(\mathrm{NH}_{2}\right)_{2} \mathrm{NNO}_{2}$

By E.K. Vasil'ev, A.N. Sapozhnivov, Z.A. Dobronravova and L.I.Vereshchagin

The Institute of the Earth's Crust, Academy of Sciences, Siberian De partment, Irkutsk 664033, U.S.S.R.

The entire concluding paragraph, part of which was missing in the original publication of this article, and the reference listings, also missing, are given below:

Compared to PDF 7-634, which was obtained by camera methods, the data in Table 2 are of higher precision and accuracy (from the use of an internal standard) in interplanar spacings, cover a wider range and contain additional weak and moderate intensity reflections.

\section{References}

Bryden, J.H., Burkardt, L.A. \& Hughes, E.W. (1956) . Acta. Crystallogr. 9, 573-578.

Bulusu, S., Dudley, R.L. \& Antera, E.W. (1987). Magn. Res. Chem. 25, 234-239.

Choi, C.S. (1981). Acta. Crystallogr. B37, 1955-1957.

Davis, T.L, Ashdown, A.A. \& Couch, H.R. (1925). J. Amer. Chem. Soc. $47,1063$.

Doll, J. \& Grison, E. (1948). Compt. Rend. 226, 679.

McCrone, W.C. (1951). Anal. Chem. 23, 205-206.

Soldate, A.M. \& Noyes, R.M. (1947). Anal. Chem. 19, 442-444.

\title{
International Report
}

Calendar of Meetings

Meeting Reports

Short Courses and Workshops

Commercial Announcements

\section{Regional Correspondents}

\section{Australia}

Mr. Tony Raftery, Dept. of Physics, Queensland Institute of Technology,

G.P.O. Box 2434, Brisbane, Queensland 4001, Australia

\section{Dr. William M. Fink}

We regret to announce the death of William M. Fink, one of the founders of the International Centre for Diffraction Data. Dr. Fink died April 2, 1992, at the age of 95 .
$118 \quad$ Czechoslavakia

120 Dr. Jaroslav Fiala, Central Research Inst., 122 SKODA, 31600 Plzen̆, Czechslovakia

123

Japan

Hideo Toraya, Ceramics Research Laboratory,

Nagoya Institute of Technology,

Asahigaoka, Tajimi 507 Japan 


\author{
Results of Election of Officers and Directors \\ JCPDS-International Centre for Diffraction Data \\ March 1992 \\ Chairman - Gerald G. Johnson, Jr. \\ Vice Chairman - Jan W. Visser \\ Treasurer - Gerhard R. Fischer \\ Chairman, Technical Committee - Ting C. Huang \\ Members-at-Large, Board of Directors \\ Thomas N. Blanton \\ Walter Eysel \\ James A. Kaduk \\ Melvin H. Meuller \\ Robert L. Snyder \\ Past Chairman - Ludo K. Frevel
}

Daniel Louër to Receive the J.D. Hanawalt Award

The JCPDS-International Centre for Diffraction Data takes pleasure in announcing that Professor Daniel Louër, Université de Rennes I, Rennes, France, has been selected to receive the J.D. Hanawalt Award for excellence in the field of powder diffraction. The presentation of the award will take place at the European Powder Diffraction Conference, EPDIC-2, Enschede, The Netherlands, JulyAugust 1992.

\section{Calendar of Meetings}

\section{2}

ICDD Clinic on X-Ray Powder Diffraction

June 1992 Fundamentals

June 1992 Advanced Techniques

Swarthmore College, Swarthmore, Pennsylvania, USA.

The ICDD X-Ray Clinics are the continuation of the SUNY Clinics which, for some twenty-five years, were held at the State University of New York at Albany. The ICDD assumed responsibility for these clinics in 1990. The Clinic is presented in two separate week-long sessions, each of which stands alone as a complete course.

Contact: Mario Fornoff, ICDD X-Ray Clinic, International Centre for Diffraction Data, 1601 Park Lane, Swarthmore, PA 19081, USA. Phone (215) 329-9400, FAX (215) 328-2503

\section{Symposium Roentgendiffraktometrie in der}

Materialwissenschaft

June 25-26, 1992

Freiberg/Sachsen, Germany

Contact: Simone Neubert, Freiberger Prazisionsmechanik GmbH, Hainichener Strasse 2 a, O-9200 Freiberg, Germany.

ICDD Clinic on X-Ray Fluorescence Spectroscopy

July 1992 Fundamentals

July 1992 Advanced Techniques

Swarthmore College, Swarthmore, Pennsylvania, USA

Details and Contact: Same as ICDD Clinic on X-Ray Powder Diffraction (above).

\section{Second European Powder Diffraction Conference} (EPDiC2)

July 30-August 1, 1992

University of Twente, The Netherlands

Contact: Chairman Scientific Program: Prof. Dr. E. Tillmans, Institute fur Mineralogie und Kristallographie der Universitat Wien, or Chairman Organizing Committee: Dr. T. W. Ryan,
Philips Analytical, Lelyweg 1, 7602 EA Almelo, The Netherlands, phone +31549039443 .

This meeting, intended as a forum for all European powder diffractionists, is scheduled to be held at the University of Twente, between Hengelo and Enschede, in the beautiful eastern part of the Netherlands, preceding the 14th European Crystallographic Meeting (ECM-14), August 3-7, 1992, at the same location. All practical and theoretical aspects of powder diffraction are welcome. The subjects of Glass and amorphous substances, Electron diffraction, Thin films, Synchrotron radiation, Stress analysis, and Structure determination from powder data will be highlighted.

14th European Crystallographic Meeting (ECM-14) August 2-7, 1992

Enschede, The Netherlands

Contact: ECM-14, Dr. H.J. Bruins Slot, Secretary, CAOS/ CAMM Center, University of Nijmegen, Toernooiveld, 6525 ED Nijmegen, The Netherlands

\section{Annual Denver Conference on Applications of X-Ray Analysis \\ August 3-7, 1992 \\ Colorado Springs, Colorado, USA}

Contact: Lynne Bonno, Conference Secretary, Department of Engineering, University of Denver, Denver, CO 80208, USA. Phone (303) 871-3515.

Special sessions include the Plenary Session on Grazing Incidence X-ray Characterization of Materials, Low Atomic Number XRF (Be-F) and Chemical State Analysis, On-Line Application of X-ray Analysis, Applications of XRF to Industrial Processes, Imaging/Tomography, Applications of Total Diffraction Patterns, High Temperature Non-ambient X-ray Diffraction, Polymer Diffraction, and X-ray Stress Analysis. Tutorial Workshops (1/2 day unless otherwise noted) scheduled are Calibration and Maintenance of X-ray Spectrometers; XRF Sample Preparation (one day); Use of Pure Intensities for XRF Math Corrections; X-ray Microbeam Imaging and Analysis; Alignment and Calibration of Diffractometers; 